\title{
ENVELHECIMENTO ACELERADO EM SEMENTES DE RÚCULA (Eruca sativa L.) ${ }^{1}$
}

\author{
NILZA PATRÍCIA RAMOS²; EBERT PEPE OBANDO FLOR ${ }^{2}$; \\ ELISABETH APARECIDA FURTADO DE MENDONÇA ${ }^{3}$; KEIGO MINAMI ${ }^{4}$
}

\begin{abstract}
RESUMO - O presente trabalho teve por objetivo avaliar a eficiência do teste de envelhecimento acelerado para a determinação do potencial fisiológico de sementes de rúcula. Foram utilizados cinco lotes de sementes, submetidos aos testes de germinação, primeira contagem da germinação, emergência de plântulas, velocidade de germinação e de emergência de plântulas e envelhecimento acelerado, empregando-se os períodos de exposição de 48,72 e 96 horas, nas temperaturas de $41^{\circ} \mathrm{C}$ ou $45^{\circ} \mathrm{C}$, com e sem o uso de solução saturada de $\mathrm{NaCl}$. O teste de envelhecimento acelerado permite classificar lotes de sementes de rúcula em diferentes níveis de vigor e dentre os procedimentos adotados, o período de exposição de 48 horas a $41^{\circ} \mathrm{C}$, com o uso de água ou de solução saturada de $\mathrm{NaCl}$, é adequado para avaliação do potencial fisiológico de sementes de rúcula.
\end{abstract}

Termos para indexação: hortaliça, análise de sementes, potencial fisiológico, vigor.

\section{ACCELERATED AGING OF Eruca sativa L. SEEDS}

\begin{abstract}
The objective of the present study was to investigate the methodology of the accelerated aging test to evaluate the physiological quality of salad rocket (Eruca sativa L.) seeds, cv. Cultivada. Five lots of salad rocket seeds were tested for germination, seedling emergence, speed germination and emergence rates and accelerated aging (periods of 48 , 72 and 96 hours, at 41 and $45^{\circ} \mathrm{C}$, with or without the use of saturated solution of $\mathrm{NaCl}$ ). Accelerated aging (with and without salt) ranked different vigor levels among seeds lots, and among the protocols studied, the period of $48 \mathrm{~h}$ at $41^{\circ} \mathrm{C}$, with the use of water or the saturated solution of $\mathrm{NaCl}$, was considered appropriate to assess the physiological quality of salad rocket seeds, cv. Cultivada.
\end{abstract}

Index terms: vegetables, seed, analysis, physiological potential, vigour.

\section{INTRODUÇÃO}

Trabalhos científicos envolvendo sementes de rúcula são escassos tanto no Brasil como no exterior. Esta cultura vem, porém, destacando-se entre as hortaliças pela sua composição nutricional, com altos teores de potássio, enxofre, ferro e de vitaminas A e C, e pelo sabor picante e odor agradável (Trani \& Passos, 1998).

No estado de São Paulo, o consumo da rúcula tem aumentado a cada ano; sendo que em 1997, o CEAGESP recebeu para comercialização 140 mil dúzias de maços e em 2001 aumentou para 448 mil (CEAGESP, 2002), com previsão de crescimento para os próximos anos. O volume comercializado triplicou no período de 1997 a 2000, indicando $\mathrm{o}$ interesse por parte da população e comprovando sua importância econômica entre as demais

\footnotetext{
${ }^{1}$ Submetido em 21/08/2003. Aceito para publicação em 12/01/2004.

2,Pós-graduandos do Depto. de Produção Vegetal, - USP/ESALQ, C.P.9 - CEP:13418-900 - Piracicaba, SP. Bolsistas CAPES. E-mail: npramos@esalq.usp.br

${ }^{3} \mathrm{Dr}^{\mathrm{a}}$. , Depto de Fitotecnia e Fitossanidade - FAMEV - UFMT

${ }^{4}$ Prof. Dr., Depto de Produção Vegetal - ESALQ - USP
}

hortaliças folhosas.

A qualidade final de um produto olerícola depende, entre outros fatores, da obtenção de uma população adequada e uniforme de plantas em campo. A emergência de plântulas em campo pode variar, mesmo para lotes de semente com alta porcentagem de germinação, em função do vigor desses lotes. Estudos sobre o vigor são importantes para a agricultura, pois permitem a obtenção de estimativas do potencial fisiológico das sementes, com a identificação de diferenças significativas entre lotes, geralmente, não detectadas pelo teste de germinação.

Para hortaliças, as informações sobre o vigor das sementes são ainda mais relevantes, pois o período de armazenamento é relativamente longo, principalmente para espécies que tem grande variação no volume de produção de sementes por safra, produzindo mais em determinados anos do que em outros, enquanto a demanda por sementes, no mercado, é estável. Tanto assim que são habitualmente armazenadas em ambiente sob condições controladas, onde a temperatura e/ou umidade relativa são reduzidas, para conservar o potencial fisiológico durante o período de armazenamento. De acordo com Marcos Filho (1999a), em razão de apresentarem menores quantidades de reservas 
armazenadas, as sementes de hortaliças possuem maior propensão à deterioração após a maturidade fisiológica, sendo esta, outra razão que justifica estudos a respeito do vigor destas sementes.

Segundo Hampton \& Coolbear (1990), em hortaliças, os testes de vigor fornecem informações complementares a respeito do potencial fisiológico dos lotes favoreceu a semeadura de precisão, a eliminação do desbaste e a sincronização na maturação, que exigem maiores conhecimentos a respeito da qualidade das sementes. Desta forma, o uso de procedimentos eficientes para a avaliação do vigor, complementando as informações fornecidas pelo teste de germinação é fundamental em programas de controle de qualidade.

Entre os diversos testes de vigor, o envelhecimento acelerado vem apresentando resultados satisfatórios para determinar o potencial fisiológico de sementes, ao avaliar o desempenho de sementes quando submetidas a temperatura e umidade relativa elevadas (Delouche \& Baskin, 1973). Atualmente, o teste é utilizado para avaliar o vigor de sementes de diversas espécies (Hampton \& Tekrony, 1995) e tem sido incluído em programas de controle de qualidade conduzidos por empresas produtoras de sementes.

O princípio do teste de envelhecimento acelerado baseia-se no aumento da taxa de deterioração das sementes, pela sua exposição a níveis elevados de temperatura e umidade relativa do ar, considerados os fatores ambientais de maior influência na intensidade e velocidade de deterioração (Tekrony, 1995; Marcos Filho, 1999b). Desta forma, são consideradas mais vigorosas as sementes que se deterioram mais lentamente após serem submetidas ao envelhecimento acelerado e que, portanto, podem tolerar estresse mais acentuado e suportar melhor as condições adversas em campo e armazenamento. Entretanto, para a maioria das hortaliças e outras espécies com sementes pequenas, o envelhecimento acelerado pode apresentar certas limitações. Sementes pequenas absorvem água mais rápida desuniformemente, resultando em comportamento variável entre as sementes da amostra avaliada. Para contornar este problema, foi sugerida a exposição das sementes a soluções saturadas de sais durante a realização do teste, as quais reduzem a umidade relativa do ambiente no interior dos compartimentos individuais $(\mathrm{NaCl}-76 \%$ $\mathrm{UR}, \mathrm{KCl}-87 \% \mathrm{UR}$ ou $\mathrm{NaBr}-55 \%$ UR), retardando a absorção de água pelas sementes. Este método, proposto por Jianhua \& McDonald (1996) é denominado teste de envelhecimento acelerado com uso de soluções saturadas de sal.

Estudos sobre o teste de envelhecimento acelerado para determinar o potencial de emergência de plântulas foram realizados para cebola (Lima, 1993; Idiarte, 1995; Piana et al., 1995), além de outras hortaliças como cenoura (Spinola et al., 1998), tomate (Rodo et al., 1998), quiabo (Torres et al., 1998), brócolos (Mello et al., 1999), maxixe (Torres \& Marcos Filho, 2001), revelando estreita relação entre os resultados obtidos nos testes de emergência de plântulas e de envelhecimento acelerado.

A utilização de soluções saturadas no teste de envelhecimento acelerado foi eficiente na classificação do vigor de lotes de sementes de milho doce (Bennett et al., 1998), pimentão (Panobianco \& Marcos Filho, 1998), cenoura (Rodo et al., 2000), pepino (Bhering et al., 2000), tomate (Panobianco \& Marcos Filho, 2001) e cebola (Rodo, 2002). Por outro lado, Ribeiro \& Carvalho (2001) não obtiveram resultados satisfatórios com esse procedimento, trabalhando com sementes de alface, brócolos e cenoura.

Diante do exposto, o presente trabalho teve como objetivo avaliar a eficiência do teste de envelhecimento acelerado (tradicional e com solução saturada de sal), para determinação do potencial fisiológico de lotes de sementes de rúcula.

\section{MATERIAL E MÉTODOS}

A pesquisa foi conduzida no Laboratório de Análise de Sementes e no Campo Experimental do Departamento de Produção Vegetal da Escola Superior de Agricultura "Luiz de Queiroz", USP, em Piracicaba - SP, no período de outubro a dezembro de 2001. Foram utilizados cinco lotes de sementes de rúcula, cv. Cultivada, submetidos aos seguintes testes.

Teor de água - realizado com duas subamostras de dois gramas de sementes para cada lote, pelo método da estufa a $105^{\circ} \mathrm{C} \pm 3^{\circ} \mathrm{C}$, durante 24 horas, de acordo com as Regras para Análise de Sementes - RAS (Brasil, 1992). Os resultados foram expressos em porcentagem (base úmida).

Germinação - conduzida com oito subamostras de 50 sementes para cada lote, distribuídas sobre duas folhas de papel mata-borrão umedecidas com água destilada, na proporção de 2,5 vezes o peso seco do papel, mantidas em caixas plásticas para a germinação, a $20^{\circ} \mathrm{C}$. As avaliações foram realizadas no quinto e décimo dia após a semeadura conforme as RAS (Brasil, 1992).

Primeira contagem da germinação - realizada conjuntamente com o teste de germinação, sendo a contagem realizada no quinto dia após sua instalação e, os resultados, expressos em porcentagem de plântulas normais (Nakagawa, 1999).

Índice de velocidade de germinação determinado mediante a contagem diária do número de plântulas normais identificadas no teste de germinação. As avaliações foram realizadas até a estabilização do número de plântulas no teste e o cálculo do índice de velocidade foi efetuado de acordo com Maguire (1962).

Emergência de plântulas - avaliada em oito subamostras de 50 sementes por lote, distribuídas em bandejas de poliestireno expandido com células individuais preenchidas com substrato comercial. A temperatura ambiente observada foi de, aproximadamente, $25^{\circ} \mathrm{C}$, em casa de vegetação dotada de nebulização intermitente. As 
avaliações foram realizadas aos 14 dias após a semeadura, computando-se as plântulas normais (tamanho igual ou superior a $1,0 \mathrm{~cm}$ ) e os resultados expressos em porcentagem de plântulas normais.

Índice de velocidade de emergência de plântulas - realizado em conjunto com o teste de emergência de plântulas pela contagem diária do número de plântulas emergidas até a estabilização da emergência e cálculo do índice de velocidade de emergência realizado conforme Maguire (1962).

Envelhecimento acelerado (tradicional) conduzido com a utilização de caixas plásticas para germinação, como compartimento individual (minicâmaras), contendo $40 \mathrm{~mL}$ de água em seu interior, uma bandeja de tela de alumínio, onde as sementes $(4,0 \mathrm{~g})$ foram distribuídas formando uma camada uniforme sobre a superfície da tela. As caixas foram mantidas em incubadora por três períodos de envelhecimento (48, 72 e 96 horas) a 41 e $45^{\circ} \mathrm{C}$. Decorrido cada período de envelhecimento, oito subamostras de 50 sementes por tratamento foram colocadas para germinar, seguindo metodologia descrita para o teste de germinação. A avaliação foi realizada no quinto dia após a semeadura, computando-se a porcentagem de plântulas normais. Foi determinado também, o teor de água das sementes após o período de envelhecimento, visando avaliação da uniformidade das condições do teste.

Envelhecimento acelerado (com uso de solução saturada de sal) - conduzido de forma semelhante ao descrito para o procedimento tradicional, adicionando-se, porém, ao fundo de cada caixa plástica, $40 \mathrm{~mL}$ de solução saturada de $\mathrm{NaCl}$ (40 g do sal em cada $100 \mathrm{~mL}$ de água), estabelecendo um ambiente com $76 \%$ de UR, seguindo a metodologia descrita por Jianhua \& McDonald (1996).

Cada procedimento (combinação de temperatura, período de exposição e solução adicionada às caixas plásticas) estudado para o teste de envelhecimento acelerado foi avaliado individualmente, sendo os lotes considerados os tratamentos, com a finalidade de verificar qual o procedimento que classifica melhor os lotes de sementes de rúcula, quanto ao vigor. Assim, o delineamento experimental utilizado foi o inteiramente casualizado com cinco tratamentos e oito repetições e as médias obtidas foram comparadas pelo teste Tukey, a $1 \%$ de probabilidade. Nos demais testes, ou seja, germinação, primeira contagem da germinação, emergência de plântulas, índice de velocidade de germinação e índice de velocidade de emergência procedeu-se, também, a comparação de médias por Tukey a $1 \%$ de probabilidade. Para a execução das análises estatísticas foi utilizado o programa estatístico ESTAT (Kronka \& Banzatto, 1995) e os valores em porcentagem dos testes de germinação, emergência e envelhecimento acelerado foram transformados em arc $\operatorname{sen} \sqrt{x / 100}$.

\section{RESULTADOS E DISCUSSÃO}

Os resultados da Tabela 1 indicaram diferenças significativas entre os lotes de sementes de rúcula cv. Cultivada, permitindo nos testes de primeira contagem da germinação e emergência de plântulas destacar os lotes A, $\mathrm{B}$ e $\mathrm{E}$ como de potencial fisiológico superior, o lote $\mathrm{D}$ como inferior e o lote $\mathrm{C}$ como intermediário. A discordância entre os resultados obtidos nos testes sugere, justamente, a necessidade de realização do maior número possível de testes antes de classificar os lotes quanto ao potencial fisiológico, pois cada teste tem um princípio diferente e fornece informações complementares para a decisão a respeito do destino final de cada lote de sementes.

TABELA 1. Qualidade inicial dos lotes de sementes de rúcula pelo teor de água (TA), teste de germinação (TG), primeira contagem da germinação (PC), emergência de plântulas (EP), índice de velocidade de germinação (IVG), índice de velocidade de emergência (IVE). Piracicaba - SP, 2001.

\begin{tabular}{|c|c|c|c|c|c|c|}
\hline \multirow{2}{*}{ Lote } & \multirow{2}{*}{ TA } & TG & $\mathrm{PC}$ & \multirow{2}{*}{ EP } & \multirow{2}{*}{ IVG } & \multirow{2}{*}{ IVE } \\
\hline & & \multicolumn{2}{|c|}{$(\%)$} & & & \\
\hline A & 6,5 & $80 \mathrm{a}$ & $47 \mathrm{ab}$ & $77 \mathrm{a}$ & $13,1 \mathrm{a}$ & $8,1 \mathrm{~b}$ \\
\hline B & 6,9 & $75 \mathrm{a}$ & $54 \mathrm{a}$ & $80 \mathrm{a}$ & $11,9 \mathrm{a}$ & $11,6 \mathrm{a}$ \\
\hline $\mathrm{C}$ & 7,6 & $59 \mathrm{~b}$ & $37 \mathrm{bc}$ & $63 \mathrm{~b}$ & $9,0 \mathrm{~b}$ & $10,9 \mathrm{a}$ \\
\hline D & 7,6 & $58 \mathrm{~b}$ & $24 \mathrm{c}$ & $48 \mathrm{c}$ & $7,7 \mathrm{~b}$ & $6,1 \mathrm{~b}$ \\
\hline E & 6,9 & $81 \mathrm{a}$ & $55 \mathrm{a}$ & $88 \mathrm{a}$ & $12,2 \mathrm{a}$ & $11,7 \mathrm{a}$ \\
\hline $\mathrm{CV}(\%)$ & - & 8,9 & 24,5 & 12,3 & 10,5 & 16,8 \\
\hline
\end{tabular}

Médias seguidas de mesma letra na coluna, não diferem entre si em nível de $1 \%(* *)$ de probabilidade, pelo teste de Tukey;

$\mathrm{CV}$ - coeficiente de variação.

O teste de germinação e o índice de velocidade de germinação separaram os lotes em dois grupos, um formado pelos lotes A, B e E com desempenho superior relativamente ao grupo constituído pelos lotes C e D. Com relação ao teor de água, os valores foram semelhantes entre os lotes, variando de $6,5 \%$ a $7,6 \%$, possibilitando assim, a obtenção de resultados mais consistentes.

Examinando-se os resultados do teste de envelhecimento acelerado (Tabela 2), tanto o procedimento tradicional como o com solução saturada de $\mathrm{NaCl}$, a $41^{\circ} \mathrm{C}$, permitiram a separação dos lotes de sementes de rúcula cv. Cultivada, em função do vigor, com exceção do procedimento tradicional empregando o período de exposição de 96 horas. Os resultados obtidos no teste de envelhecimento acelerado tradicional, para todos os períodos de exposição, a $45^{\circ} \mathrm{C}$, não foram elucidativos, pois o estresse a que as sementes foram submetidas foi drástico e reduziu, acentuadamente, a porcentagem plântulas normais de rúcula, impedindo a classificação dos lotes quanto ao vigor. 
$\mathrm{O}$ teste de envelhecimento acelerado com solução saturada de sal, conduzido a $41^{\circ} \mathrm{C}$ durante 48 horas e a $45^{\circ} \mathrm{C}$ por 96 horas (Tabela 2), proporcionou a mesma separação dos lotes verificada pela emergência de plântulas (Tabela 1). Os resultados obtidos no teste de envelhecimento acelerado, conduzido de forma tradicional a $41^{\circ} \mathrm{C}$ por 72 horas, separaram os lotes em maior número de níveis de vigor, pois, além de indicar o lote A como de potencial fisiológico superior e o lote $\mathrm{D}$ como inferior, também detectou diferenças entre os lotes $\mathrm{A}, \mathrm{B}$ e $\mathrm{E}$, não verificados no teste de germinação, emergência de plântulas e em algumas combinações de temperatura e período de exposição estudados para a condução do teste de envelhecimento acelerado. Porém, ao se analisarem os valores de germinação após o envelhecimento notou-se elevada redução na porcentagem de plântulas normais, indicando que o procedimento que utiliza $41^{\circ} \mathrm{C}$ por 72 horas não é o mais adequado.

Sugere-se, portanto, o uso de 48 horas de exposição a $41^{\circ} \mathrm{C}$, pois o menor período de execução é uma característica desejável em um teste de vigor possibilita a economia de energia elétrica pelo equipamento.

Os resultados médios relativos ao teor de água atingido após a realização do teste de envelhecimento acelerado tradicional e com solução saturada de $\mathrm{NaCl}$ estão na Tabela 3. Observa-se que, sementes de rúcula envelhecidas, no procedimento tradicional, atingiram teores de água mais elevados e variações mais acentuadas, diferindo até valores de 6,8 pontos percentuais (p.p.), que excedem os limites toleráveis ( 3 a 4 p.p.), indicados por Marcos Filho (1999b). Por outro lado, verifica-se que o uso de solução saturada de $\mathrm{NaCl}$ reduziu a velocidade de absorção de água pelas sementes durante o período de envelhecimento, não excedendo a variação de 2,5 p.p. do teor de água entre os lotes envelhecidos. As condições de envelhecimento acelerado com solução salina promoveram efeitos menos drásticos, pois, ao atingir menores teores de água (máximo de $14,7 \%$ enquanto o tradicional chegou a $43,3 \%$ ), o grau de deterioração das sementes foi menor em relação ao normalmente constatado com o uso do método tradicional.

TABELA 2. Porcentagem de germinação de sementes de rúcula após o teste de envelhecimento acelerado tradicional $\left(\mathrm{H}_{2} \mathrm{O}\right)$ e com solução saturada de $\mathrm{NaCl}(\mathrm{SS})$. Piracicaba - SP, 2001.

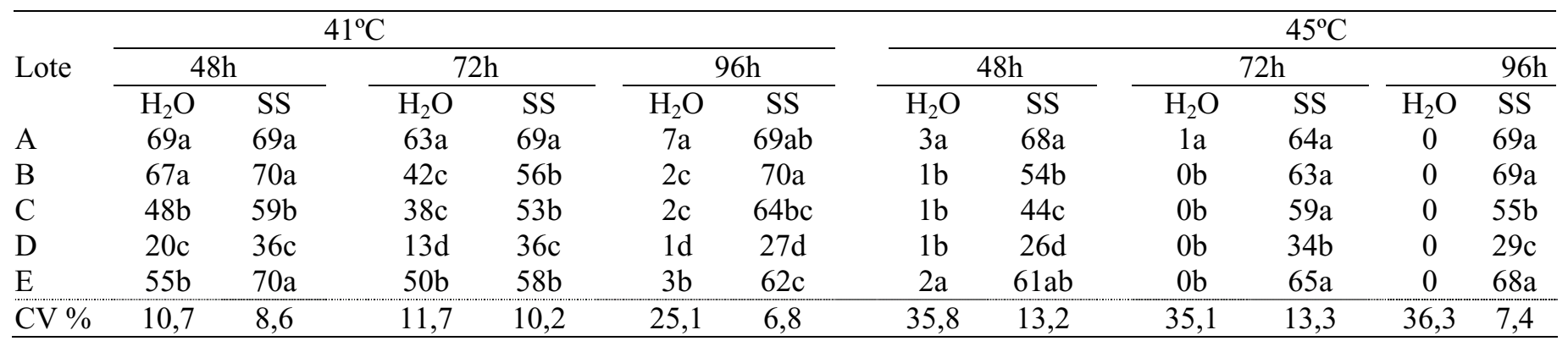

Médias seguidas de mesma letra na coluna, não diferem entre si em nível de $1 \%\left({ }^{* *}\right)$ de probabilidade, pelo teste de Tukey;

CV - coeficiente de variação.

TABELA 3. Teores de água (\%) obtidos após os períodos de envelhecimento acelerado tradicional $\left(\mathrm{H}_{2} \mathrm{O}\right)$ e com solução saturada de $\mathrm{NaCl}$ (SS) em sementes de cinco lotes de rúcula, cv. Cultivada. Piracicaba - SP, 2001.

\begin{tabular}{|c|c|c|c|c|c|c|c|c|c|c|c|c|}
\hline \multirow{3}{*}{ Lote } & \multicolumn{4}{|c|}{$41^{\circ} \mathrm{C}$} & \multirow{2}{*}{\multicolumn{2}{|c|}{$96 \mathrm{~h}$}} & & & \multicolumn{4}{|c|}{$45^{\circ} \mathrm{C}$} \\
\hline & \multicolumn{2}{|c|}{$48 \mathrm{~h}$} & \multicolumn{2}{|c|}{$72 \mathrm{~h}$} & & & \multicolumn{2}{|c|}{$48 \mathrm{~h}$} & \multicolumn{2}{|c|}{$72 \mathrm{~h}$} & \multicolumn{2}{|c|}{$96 \mathrm{~h}$} \\
\hline & $\mathrm{H}_{2} \mathrm{O}$ & SS & $\mathrm{H}_{2} \mathrm{O}$ & SS & \multicolumn{2}{|c|}{$\mathrm{H}_{2} \mathrm{O}$} & $\mathrm{H}_{2} \mathrm{O}$ & SS & $\mathrm{H}_{2} \mathrm{O}$ & SS & $\mathrm{H}_{2} \mathrm{O}$ & SS \\
\hline A & 38,9 & 11,8 & 37,2 & 9,4 & 37,2 & 9,4 & 35,9 & 10,4 & 35,8 & 10,4 & 43,3 & 9,7 \\
\hline B & 38,5 & 14,3 & 36,0 & 9,4 & 38,3 & 10,0 & 38,4 & 11,6 & 37,1 & 10,4 & 39,9 & 9,8 \\
\hline C & 39,1 & 14,7 & 38,8 & 9,7 & 38,8 & 9,5 & 36,8 & 11,6 & 38,8 & 10,1 & 40,6 & 9,9 \\
\hline D & 40,3 & 13,5 & 40,5 & 9,4 & 38,1 & 9,5 & 41,5 & 12,1 & 39,8 & 10,4 & 36,4 & 9,5 \\
\hline E & 36,6 & 13,1 & 37,2 & 9,7 & 38,1 & 10,5 & 37,9 & 12,4 & 35,6 & 10,1 & 39,7 & 9,7 \\
\hline
\end{tabular}

Desta forma, o fator mais importante para a produção do estresse, com o uso de solução salina, é a temperatura elevada. Essa hipótese foi confirmada (Tabela
2) e os resultados concordam com os obtidos por Jianhua \& McDonald (1997), Panobianco \& Marcos Filho (1998) e Santos et al. (2002). 
A elevação da temperatura promove efeitos mais drásticos na germinação do que o prolongamento do período de exposição durante o envelhecimento (Tomes et al., 1988). Observa-se que o teste conduzido a $45^{\circ} \mathrm{C}$, com água reduziu consideravelmente a germinação das sementes de rúcula em relação a $41^{\circ} \mathrm{C}$, sendo que 48 horas de exposição foram suficientes levá-las à morte; demonstrando que temperaturas de $45^{\circ} \mathrm{C}$ associada à umidade relativa de $100 \%$ são condições excessivamente estressantes para as sementes de rúcula.

Outra vantagem do emprego da solução saturada de sal é a redução do desenvolvimento de fungos durante o teste, em função da restrição na umidade relativa que desfavorece a proliferação de microrganismos. No presente trabalho, essa afirmação confirmou-se pois, com adição de solução de $\mathrm{NaCl}$ no teste não foi observada a presença de fungos. Observações semelhantes foram efetuadas por Jianhua \& McDonald (1996), Rodo et al. (2000) e Panobianco \& Marcos Filho (2001).

Portanto, os resultados deste trabalho confirmam que o uso de solução saturada de sal contribui para o aprimoramento da metodologia do teste de envelhecimento acelerado na avaliação do vigor de sementes pequenas pois, além de utilizar o mesmo equipamento do procedimento tradicional, proporciona condições para absorção de menores quantidades de água e de maneira mais uniforme pelas sementes.

\section{CONCLUSÕES}

O teste de envelhecimento acelerado permite classificar lotes de sementes de rúcula em diferentes níveis de vigor e dentre os procedimentos adotados, o período de exposição de 48 horas a $41^{\circ} \mathrm{C}$, com o uso de água ou de solução saturada de $\mathrm{NaCl}$, é adequado para avaliação do potencial fisiológico de sementes de rúcula.

\section{REFERÊNCIAS}

BENNETT, M.A.; BARR, A.J.; GRASSBAUGH, E.M.; EVANS, A.F. Seed vigor evaluation of su, se and sh2 sweet corn genotypes using the saturated salt accelerated aging test. In: CONGRESS OF ISTA, 25, Pretoria, 1998. Abstracts... Pretoria: ISTA, 1998, p.92-93.

BHERING, M.C.; DIAS, D.C.F.S.; GOMES, J.M.; BARROS, D.I. Métodos para a avaliação do vigor de sementes de pepino. Revista Brasileira de Sementes, Brasília, v.22, n.2, p.171-175, 2000.

BRASIL. Ministério da Agricultura e Reforma Agrária. Regras para análise de sementes. Brasília: SNDA/DNPV/CLAV, 1992. 365p.
COMPANHIA DE ENTREPOSTOS E ARMAZÉNS GERAIS DE SÃO PAULO. Quinquênio - preços médios e quantidades mensais: rúcula. São Paulo, 2002. (Comunicação pessoal).

DELOUCHE, J.C.; BASKIN, C.C. Accelerated aging techniques for predicting the relative storability of seed lots. Seed Science and Technology, Zürich, v.1, n.2, p.427-452, 1973.

HAMPTON, J.G.; COOLBEAR, P. Potential versus actual seed performance can vigour testing provide an answer? Seed Science and Technology, Zürich, v.18, n.2 , p.215228, 1990.

HAMPTON, J.G.; TEKRONY, D.M. Recommended seed vigour tests: Accelerated ageing test. In: HAMPTON, J.G.; TEKRONY, D.M. Handbook of vigour test methods. Zürich: ISTA, p.35-50, 1995.

IDIARTE, H.G. Relação do envelhecimento acelerado na qualidade fisiológica de sementes de cebola. Piracicaba. 1995. 84f. Dissertação (Mestrado em Fitotecnia). Escola Superior de Agricultura “Luiz de Queiroz", 1995.

JIANHUA, Z.; McDONALD, M.B. The saturated salt accelerated aging test for small seeded crops. Seed Science and Technology, Zürich, v.25, n.1 , p.123-131, 1996.

KRONKA, S.N.; BANZATTO, D.A. ESTAT: Sistema para análise estatística versão 2 . 3ed. Jaboticabal: FUNEP, 1995. 247p.

LIMA, D. Avaliação da viabilidade e vigor de sementes de cebola (Allium cepa L.). Pelotas. 1993. 61f. Dissertação (Mestrado em Agronomia). Universidade Federal de Pelotas, 1993.

MAGUIRE, J.D. Speed of germination-aid seedling emergence and vigor. Crop Science, Madison, v.2, n.1, p.176-177, 1962.

MARCOS FILHO, J. Testes de vigor: importância e utilização. In: KRZYZANOWSKI, F.C.; VIEIRA, R.D.; FRANÇA NETO, J.B. (Ed.). Vigor de sementes: conceitos e testes . Londrina: ABRATES, 1999a. p.1.1-1.21.

MARCOS FILHO, J. Teste de envelhecimento acelerado. In: KRZYZANOWSKI, F.C.; VIEIRA, R.D.; FRANÇA NETO, J.B. (ed.). Vigor de sementes: conceitos e testes. Londrina: ABRATES, 1999b. p.3.1-3.24.

MELLO, S.C.; SPINOLA, M.C.M.; MINAMI, K. Métodos para a avaliação da qualidade fisiológica de sementes de brócolos. Scientia Agricola, Piracicaba, v.56, n.4, p.11511155, 1999. (Suplemento). 
NAKAGAWA, J. Testes de vigor baseados na avaliação de plântulas. In: KRZYZANOWSKI, F.C.; VIEIRA, R.D.; FRANÇA NETO, J.B. (ed.). Vigor de sementes: conceitos e testes. Londrina: ABRATES, 1999. p.2.1-2.23.

PANOBIANCO, M.; MARCOS FILHO, J. Comparação entre métodos para avaliação da qualidade fisiológica de sementes de pimentão. Revista Brasileira de Sementes, Brasília, v.20, n.2, p.306-310, 1998.

PANOBIANCO, M.; MARCOS FILHO, J. Envelhecimento acelerado e deterioração controlada em sementes de tomate. Scientia Agricola, Piracicaba, v.58, n.3, p.525-531, 2001.

PIANA, Z.; TILLMANN, M.A.A.; MINAMI, K. Avaliação da qualidade fisiológica de sementes de cebola e sua relação com a produção de mudas vigorosas. Revista Brasileira de Sementes, Brasília, v.17, n.2, p.149-153, 1995.

RIBEIRO, F.C.; CARVALHO, N.M. The saturated salt accelerated aging method seems to act leniently on carrot, lettuce and broccoli seeds germination. In: INTERNATIONAL SEED TESTING CONGRESS - SEED SYMPOSIUM, 26, 2001, Angers. Abstracts... Zürich, ISTA, 2001. p.39-40.

RODO, A.B. Avaliação do potencial fisiológico de sementes de cebola e sua relação com o desempenho em campo. Piracicaba. 2002. 123f. Tese (Doutorado em Fitotecnia). Escola Superior de Agricultura "Luiz de Queiroz", 2002.

RODO, A.B.; PANOBIANCO, M.; MARCOS FILHO, J. Metodologia alternativa do teste de envelhecimento acelerado para sementes de cenoura. Scientia Agricola, Piracicaba, v.57, n.2, p.289-292, 2000.

RODO, A.B.; TILLMANN, M.A.A.; VILLELA, F.A. Testes de vigor na avaliação da qualidade fisiológica de sementes de tomate. Revista Brasileira de Sementes,
Brasília, v.20, n.1, p.23-28, 1998.

SANTOS, P.M.; GONDIM, T.C.O.; ARAUJO, E.F.; DIAS, D.C.F.S. Avaliação da qualidade fisiológica de sementes de milho doce pelo teste de envelhecimento acelerado. Revista Brasileira de Sementes, Londrina, v.24, n.1, p.91-96, 2002.

SPINOLA, M.C.M.; CALLIARI, M.F.; MARTINS, L.; TESSARIOLI NETO, J. Comparação entre métodos para avaliação do vigor de sementes de cenoura. Revista Brasileira de Sementes, Brasília, v.20, n.2, p.301-305, 1998.

TEKRONY, D.M. Accelerated ageing. In: VENTER, H.A. Seed Vigour Testing Seminar, Copenhagen, Denamark, p.53-73, 1995.

TOMES, L.J.; TEKRONY, D.M.; EGLI, D.B. Factors influencing the tray accelerated aging test for soybean seed. Journal of Seed Technology, East Lansing, v.12, n.1, p.24$35,1988$.

TORRES, S.B.; MARCOS FILHO, J. Teste de envelhecimento acelerado em sementes de maxixe (Cucumis anguria L.). Revista Brasileira de Sementes, Londrina, v.23, n.2, p.108-112, 2001.

TORRES, S.B.; CASEIRO, R.F.; RODO, A.B.; MARCOS FILHO, J. Testes de vigor em sementes de maxixe (Cucumis anguria $\mathrm{L}$.) com ênfase ao teste de condutividade elétrica. Revista Brasileira de Sementes, Brasília, v.20, n.2, p.480-483, 1998.

TRANI, P.E.; PASSOS, F.A. Rúcula (Pinchão). In: FAHL, J.I.; CAMARGO, M.B.P.; PIZINATTO, M.A.; BETTI, J.A.; MELO, A.M.T.; DEMARIA, I.C.; FURLANI, A.M.C. (Ed.) Instruções agrícolas para as principais culturas econômicas. Campinas: IAC, 1998. p.241-242. (Boletim, 200).

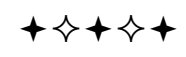

